\title{
The Challenge of Challenges
}

\author{
Michèle Finck ${ }^{*}$ and Floris de Witte ${ }^{* *}$
}

\section{A. Introduction}

European Union law is an endangered discipline. To some extent, it is becoming impossible to be a generalist EU lawyer-whose expertise spans the many different policy fields that EU law engages in. EU law is, to use its own parlance, both widening and deepening very quickly — whereby whole new fields such as animal rights, digital contracts or criminal law theory are drawn into its orbit. The study of European Union law is, at the same time, becoming more comfortable with crossdisciplinary work, and is showing a renewed focus on critical engagement, empirical work, and historical analysis.

These changes take place against the backdrop of a European Union that is stumbling from crisis to crisis - even if, perhaps, the language and rhetoric of crisis has accompanied the integration process from the very start. The answers given to the Euro-crisis and the refugee crisis-using the word "solution" instead would be too generous - the rule of law crisis, the general rise in Euroskepticism and disillusion with integration feed into a process that is highly volatile and unpredictable. It is becoming increasingly difficult not just to understand what is happening, but also why it is happening, and what all of it means for the future of the integration project. One thing is clear to us, however. This moment of flux is meaningful in and of itself — and it is being used as a catalyst for a discussion about the orientation of the integration process, but also of the role of the academy in it. ${ }^{1}$ It feels, in short, very much like the end of one part of the process of integration; and the beginning of another one.

The German Law Journal thought that, with the new decade starting, it would be a good idea to take stock, to do a sort of vox pop of European Union law scholarship about the direction of integration. We have asked colleagues-young and established; generalists and specialists-for their take on the main challenge for the EU in the 2020s. That's all we asked. We specified that the contributions be short, but left the topic, style, argument and approach in the hands of the authors. In doing so, we hoped to unearth not just a diversity of topics-plenty of challenges to choose from, it seems - but also a diversity of styles, types of engagement, and an interesting synergy and conflict between the different contributions. And so it transpired.

In this special issue you will find all the contributions. The range is as we had hoped-from how to tackle emerging policy challenges of computational intelligence and climate change to reconceptualizations of the normative underpinnings of European integration. Some contributions stress the need to rediscover who we, the citizens, are, and how we can live together in Europe, and in the world, of 2020. Others offer new ways for academics to engage with integration, while others yet stress the distributive consequences of integration and emerging contradictions in specific fields of EU policy. We have seen a surprising amount of focus on institutional change-pulling

\footnotetext{
${ }^{\star}$ Senior Research Fellow at the Max Planck Institute for Innovation and Competition.

${ }^{* *}$ Associate Professor at the London School of Economics and Political Science.

${ }^{1}$ Floris de WitTe, RE:Generation Europe (2020); Antoine Vauchez et al., Manifesto for the Democratization of Europe, http://tdem.eu/en/manifesto/ (last visited Nov. 29, 2019); Alberto Alemanno, The Good Lobby, http://thegoodlobby.eu/ (last visited Nov. 29, 2019).
}

(c) The Author(s) 2020. Published by Cambridge University Press on behalf of the German Law Journal. This is an Open Access article, distributed under the terms of the Creative Commons Attribution licence (http://creativecommons.org/licenses/by/4.0/), which permits unrestricted re-use, distribution, and reproduction in any medium, provided the original work is properly cited. 
in different directions. All in all, it makes for a fascinating collection of ideas, challenges and meditations that will no doubt inspire our discipline to push itself in the new decade to offer new ways to think about, alter, and assess the path that integration takes.

\section{B. In this Issue}

The various contributors to this special issue had complete freedom to choose a challenge for the EU in the 2020s that they wanted to write about. The result is a rich catalogue of topics and perspectives.

Some of the authors have written about those challenges that have ranked high in media debates in the past months and years. Liz Fisher writes about the EU's climate change regime and urges us to resist thinking of climate change as an elitist project. Rather, she cautions us to ensure that actions taken do not reinforce popular disenchantment and manage disruptions in a way that is as fair as possible. Joanne Scott looks at the EU's role in environmental destruction, highlighting that the EU has a large and damaging environmental footprint given its reliance on resources from outside its borders. She documents the measures that the Union has taken to remedy this, stressing that these give rise to territorial extension. Cathryn Costello highlights a second European challenge that has been widely discussed: The refugee crisis. Her contribution, however, provides a strong rejection of the "crisis" narrative, arguing that speaking of "atrocity" would be more appropriate. Gráinne de Búrca suggests that an EU citizens' assembly on refugee law and policy, modelled after recent experiences with such processes in Ireland, could help remedy the familiar democratic deficiencies of the EU in this area.

Another cluster of contributions addresses institutional challenges. Koen Lenaerts is defending the "integration through the rule of law" narrative and puts forward that it defines what the European Union stands for, arguing that integration can only occur where the Union and its Member States respect the "rules of the game". Alberto Alemanno looks at Europe's democratic challenge in asking how citizen participation is best organized in and beyond elections. Diamond Ashiagbor analyses the way in which transnational regulation can serve as a source for the EU's authority in the era of Brexit and Trump. Antoine Vauchez writes about the phantom "European public" and calls for an interdisciplinary reorientation of the field of European law and European studies.

Other scholars chose to reflect on the very essence of the integration process. Mark Dawson asks if the EU's biggest challenge is perhaps still its original one: The continued relevance of the EU's rule-making and adjudicative capacity in the face of existential threat. Marija Bartl pinpoints that despite decades of integration, the EU has never grown into a democratic political community and reflects on the impediments of and conditions for the emergence of a pan-European political space. Franz Mayer attempts to anticipate future developments in EU law, arguing that the task may not be one of achieving ever more integration but rather in upholding what has already been achieved. Valsamis Mitsilegas chose to think about different dimensions of trust in the integration process and way in which trust undergirds the EU's principles and values.

Others have reflected on ongoing technological developments and their impact on the EU. Mireille Hildebrandt draws on philosophy to question the terminology of "artificial intelligence" and reflects on the commonalities and divergences between human and artificial intelligence. Orla Lynskey ponders the metamorphosis of data protection law and particularly the CJEU's role in that process. She warns that data protection law must not become part of legitimizing exploitative data processing practices. Instead, it should serve to disrupt such exploitative business models and practices.

Finally, a last set of contributors looked at specific topics. Silvana Sciarra documents current and upcoming challenges and opportunities in EU social law, whereas Irma Mosquera Valderrama documents how the area of direct taxation has been subject to change since the 
financial crisis. The final two contributions invite us to think about the role of values in the EU. J.H.H. Weiler warns us that when writing and thinking about populism, it is a mistake to reduce the human being to her material needs only, to the exclusion of metaphysical needs and the quest for significance and meaning in life. The critique of patriotism and nationalism should thus not become a critique of collective values. Loïc Azoulai reflects on the defense of European values, such as through a Commissioner in charge of defending the "European way of life", and suggests that in light of current societal and political sentiments, an abstract defense of such values in untenable.

The special issue underlines that the European Union does not currently lack in challenges. Whereas some of these challenges are the result of our specific times, others-such as the tension between universalism and particularism, or humankind's paradoxical dependence on, and destruction of, its natural habitat-are challenges that might simply be intrinsic to the human condition. Thinking about how the EU can propel itself to meet these challenges, and how it can give shape to this new phase of European integration, requires us, as Liz Fisher highlights in her contribution, quite literally to re-learn how we can be in this world. As many of the contributions to this special issue highlight, we need to re-learn what matters to us, how we can think and talk about the future of Europe, and how we can shape the process of integration in a manner beneficial to all.

\section{The Challenge of Challenges}

But re-learning how to be is not an easy task. It presupposes, among other things, the willingness and ability to look at one's own pathologies. It also presupposes an awareness of how changes in the environment might necessitate changing methods of response. This is a challenge that is significant for the EU in general, and for EU law specifically. EU law has come to govern so many different, contradictory and salient questions and policy domains, all of which come with their own assumptions, tensions and nuances. How can EU law make sense of all these? Can EU law even make sense of this at all? Can it do so while retaining a sense of coherence and order that seems to have guided its development so far? Can it show sufficient flexibility and sensitivity to context to allow it to structure European society in a fashion that is considered appropriate by its subjects?

European integration, and its legal order, have always been predicated on the need to overcome difference. Difference within Europe and between Europeans, the argument runs, inhibits cooperation-while similarity breeds trust and facilitates the pursuit of the "ever closer union" among the peoples of Europe. The harmonization of whole policy domains; the functional nature of the competences of the EU; the structure and nature of its legal order; the use of judicial doctrines such as "effet utile" or "a certain degree of integration"; its obsession with uniformity and justiciability; or the centralizing effects of EMU reform are all examples of this tendency to equate the overcoming of difference with integration. We integrate by overcoming difference. We become strong by overcoming difference. This vision, obviously, has potentially very strong centrifugal effects. The EU's reliance on law to secure integration, moreover, has equally strong centralizing tendencies. EU law now contains - explicitly or implicitly-very specific understandings of solidarity, morality, security, the "good" citizen and the "bad" citizen, that at times conflict with and supplant thicker visions of these notions on the national level. More generally, EU law has a highly prescriptive, but also partial and selective vision of the subject and her life-world.

All these centrifugal processes are not particularly surprising: We know that these elements are building blocks in the process of system formation-just as the strengthening of external borders or internal monetary capacity are. The recent focus on the "values" of the EU, which re-emerged within the context of the constitutional changes taking place in Poland and Hungary, further exemplifies this gradual but unmistakable process of solidification of the EU's center: In its 
institutions, its values, its coercive capacity and its very ethos. The EU now has "a way of life", a Commissioner protecting that "way of life", just as it has made sure that the light bulbs bought in Seville or Poznan are of similar quality; and the data protection settings on TikTok are alike whether in Athens or Dublin. This pursuit of coherence and order, certainty and similarity is the pursuit of European integration. Achieving integration is achieving complete order.

Except that, of course, Brexit has taught us that when the Speaker of the House insists on "Order! Order! Ooooooorder!"; we are usually faced with the exact opposite: We are faced with chaos, passion, conflict and contestation. Such is increasingly the environment within which European integration takes place. While the world is changing around the EU-with ever greater disillusion with contemporary politics, an increase in distributive and identity conflicts, and the refugee and climate crises showing no signs of abating - the EU itself is not changing. Its leaders still preach order and coherence, the Commission sees the changes in the environment as challenges to the "European way of life", while the ECB and CJEU continue to see these challenges as requiring ever greater coherence across the Member States and their policies. All this is not to say that the EU has caused the disorder that marks contemporary politics. Nor is it to belittle the extraordinary accomplishments of European integration and the absolute necessity of inter-state cooperation to face the challenges of the next century. It is, instead, to say that the EU must be sensitive to what the changes to the conditions under which integration takes place mean for the way in which integration can take place. If, to put it simply, the world around the EU is changing, the EU must change with it.

The pages that follow are full of ways in which the EU could embrace change. Engaging with the changing environment within which integration takes place, rather than "ordering away" any such challenges, could bolster the EU's institutional legitimacy, its authority, its ability to answer salient policy questions, and its very stability. But that requires-quite literally-thinking differently. One example suffices here, before we give the floor to our contributors. Since 2001, the EU has centralized the authorization process before genetically modified organisms (GMOs) can be released on its market. Despite several GMOs passing the Commission's and the European Food Safety Authority (EFTA)'s scientific scrutiny unopposed, and deemed safe to be released in the environment, at least nineteen Member States simply refused to accept such release within their territories, citing the need to protect agrarian practices, the viability of biological farming, pressure from grassroot movements, and a general skepticism on the role of such technology in the agricultural process. In 2015, a new Directive was adopted, on the basis of Article 114 TFEU—which, remember, is to be used to remove barriers to trade on the internal market-explicitly allowing Member States to ban the release of GMOs considered safe within their domestic territory for reasons including "environmental policy", "land use", "town and country planning", or "socioeconomic impacts". ${ }^{2}$ Without going too far into the detail of this example, this offers a wonderful insight into what the EU might look like once it moves beyond its focus on order, coherence, and centralization. An EU that can be sensitive to contestation where it occurs, understands context, opens up space and language within EU law for difference, and allows stakeholders to understand the process of integration as a process that engages with its very own environment.

${ }^{2}$ Council Directive 2015/412, art. 1(2), 2015 O.J. (L 68) 1.

Cite this article: Finck M, de Witte F (2020). The Challenge of Challenges. German Law Journal 21, 1-4. https://doi.org/ 10.1017/glj.2019.86 